\title{
Two types of most
}

\author{
Carmen Dobrovie-Sorin \\ CNRS-LLF, Université Paris 7
}

\begin{abstract}
The empirical puzzle to be solved is the contrast between partitive and non-partitive most (which respectively take of-DP and NP restrictors, respectively) wrt their compatibility with a collective predicate (or a collectively interpreted mixed predicate) in the nuclear scope. The proposal will rely on the 'null hypothesis' regarding the correspondence between syntactic categories and semantic type: DPs and NPs respectively denote entities and sets of entities. Our puzzle will be solved by explaining why set-restrictor quantifiers cannot denote relations between sets of plural entities whereas entity-restrictor quantifiers can denote relations between plural entities. It will also be argued that plural bare NPs in the restrictor of most can be kind-denoting (in addition to being setdenoting) in English. Throughout the paper the main generalizations will be strengthened or refined by taking into account the Romanian counterparts of the relevant data.
\end{abstract}

Keywords: collective quantification, mass quantification, bare mass NPs, bare plurals, kind-reference

\section{Introduction}

The contrast in (1), observed by van der Does (1993: 531), is a refinement of Roberts' (1987) claim that most does not allow collective predicates in the nuclear scope. Van der Does's observation is that Roberts is right for non-partitive most, but not for partitive most: ${ }^{1}$

(1) a. *Most [ ${ }_{\mathrm{NP}}$ boys] gathered in this room.

b. Most of [ ${ }_{\mathrm{DP}}$ the boys] gathered in this room.

* For comments on previous versions of this work I would like to thank Lucas Champollion, Ileana Comorovski, Ion Giurgea and Anna Szabolcsi. The research reported here was partially supported by the program Investissements d'Avenir, overseen by the French National Research Agency, ANR-10-LABX-0083, (Labex EFL).

1 Van der Does's example (1993: 531) is Most of the boys left together, built on Roberts' example *Most boys left together. I have changed it because Ileana Comorovski observed that van der Does' example was not fully acceptable, maybe not acceptable at all for certain speakers. However, the relative unacceptability of some examples does not threaten the generalization that collective predicates are allowed only with partitive most, not with non-partitive most. 
If my understanding of van der Does 1993 is correct, his proposal does not explain the contrast that he observed, but instead provides a set-theoretical analysis of examples of the type in (1)b. Although there are well-known correspondences between mereological and set-theoretical frameworks (due to the correspondence between the part of and the subset relations), the set-theoretical approach cannot account for mass Qs, and as such does not offer an adequate background for the present paper, which argues, following Dobrovie-Sorin 2014, that collective quantifiers (i.e., plural quantifiers that take collective predicates or collectively interpreted mixed predicates in the nuclear scope) are of the same semantic type as mass quantifiers. The proposal to be made in this paper will implicitly assume an algebraic mereological approach to pluralities. To the best of my knowledge, the contrast in (1) has not been taken up since van der Does 1993. Indeed, although Crnič (2009) does address the contrast between partitive and non-partitive most wrt cumulative readings and collective readings of mixed predicates (i.e., those predicates that can be true of either singular or plural entities), he explicitly sets aside collective predicates such as gather.

Section 2 makes explicit the syntax-semantics mapping. In Section 3 we adopt the generalized quantifier theory for the set-restrictor most and we explain why collective quantifiers cannot denote relations between sets of plural entities. In Section 4 we examine the entity-restrictor most, and we show that this type of quantifier can function as a collective quantifier. Section 5 shows that bare NPs in the restrictor of most can be kind-referring in English but not in Romanian, which explains why collective quantification is allowed in such configurations in English, but not in Romanian. The data examined in that section argue against Matthewson's (2001) claim that bare NPs in the restrictor of most are always kind-referring in English and against Crnic's (2009) view that the distributive readings of mixed predicates in the nuclear scope of most are due to the kindreference of the restrictor.

\section{Syntax-semantics interface}

I will assume a Generalized Quantifier analysis for both partitive and nonpartitive most $^{2} \cap$ notates the lattice-theoretic operation meet (intersection is meet applied to sets):

(2) The relation $\operatorname{MOST}(\mathrm{A}, \mathrm{B})$ holds iff $|[[\mathrm{A}]] \cap[[\mathrm{B}]]|>|[[\mathrm{A}]]-[[\mathrm{A}]] \cap[[\mathrm{B}]]|$

\footnotetext{
${ }^{2}$ The fact that most is the superlative of much/many lead Hackl (2009) to propose that proportional most is not a quantificational Determiner (contra the GQT analysis) but rather an adjective (both syntactically and semantically). For crosslinguistic empirical evidence against the adjectival status of proportional MOST see Dobrovie-Sorin 2013 and Dobrovie-Sorin \& Giurgea 2015.
} 
Two types of most

The two quantifiers nevertheless differ regarding the syntactic category of their restrictor: Partitive most is built with a DP-restrictor, and non-partitive most with an NP-restrictor. I will assume the uncontroversial syntactic category-semantic type correspondences given in (3) and I will not assume type-shifting in the restrictor, as stated in (4):

(3) a. NPs denote sets.

b. DPs denote entities.

(4) Type-shifting cannot apply to the restrictor of a quantifier.

Given (4), non-partitive and partitive most must respectively be analyzed as setrestrictor and entity-restrictor quantifiers (but note that (5)a will be refined in Section 5):

(5) a. Non-partitive most (most $N P_{p l}$ ) is a set-restrictor quantifier.

b. Partitive most (most of $D P_{p l}$ ) is an entity-restrictor quantifier.

The contrast in (1) can now be described as follows:

(6) a. The set-restrictor most does not allow a collective predicate in its scope.

b. The entity-restrictor most allows a collective predicate in its scope.

The main goal of the paper will be to explain these two generalizations.

\section{Set-restrictor most}

\subsection{The Generalized Quantifier analysis of most}

According to the Generalized Quantifier analysis of most, examples of the type in (7) are true iff (8) is satisfied:

(7) Most students in my class left early.

(8) $|\{x: \operatorname{student}(\mathrm{x})\} \cap\{\operatorname{left}-\operatorname{arl} \mathrm{y}(\mathrm{x})\}|>\mid\{\mathrm{x}: \operatorname{student}(\mathrm{x})\}-\{\mathrm{x}: \operatorname{student}(\mathrm{x})\} \cap$ $\{$ left-early $(\mathrm{x})\} \mid$

(8) says that the set of students in my class for which the property denoted by the VP (left early) is true has a greater cardinality than the complement of that set wrt the set of all students in my class.

Note that although students is a plural-marked NP, it is assumed to denote a set of singular entities rather than a set of pluralities. I take DP-internal plural morphology on the NP to be semantically empty. ${ }^{3}$

3 Plural morphology on DP-internal NPs is triggered by agreement with cardinals and with MANY (including its comparative and superlative forms) in certain languages (Romance, Germanic) but not in others, e.g., Hungarian, in which cardinals, as well as an invariable form 


\subsection{Set-restrictor most with collective predicates in the nuclear scope}

Let us now examine the unacceptable example in (1)a, repeated under (9), which illustrates the ban on the set-restrictor most built with a collective predicate in the nuclear scope:

(9) *Most [NPboys] gathered in this room.

The observation is replicated in Romanian, where cei mai mulţi 'the more many', the superlative of multi 'many', is the semantic counterpart of English most:

(10) *Cei mai mulţi băieţi s-au adunat în sala asta.

THE MORE MANY boys SE have gathered in room-the this

Note that cei mai multi does allow the proportional reading 5 in examples corresponding to the English (7), in which the nuclear scope is filled with a distributive predicate:

(11) Cei mai mulţi elevi din clasa mea au plecat devreme.

THE MORE MANY students in class-the my have left early

'Most students in my class left early.'

Examples of the type in (11) are to be analyzed on a par with the English example in (7), as relying on the Generalized-Quantifier analysis of MOST (capitals notate most and its crosslinguistic counterparts) shown in (8).

In order to explain the unacceptability of (9) and (10) let us examine the condition in (12), built on the model of (8), which would need to be satisfied in order for (9) and (10) to be true: ${ }^{6}$

for MUCH combine with unmarked NPs, e.g., három fiú 'three boy' and sok fiú 'much boy' meaning 'three boys' and 'many boys', respectively.

${ }^{4}$ Romanian superlatives are built like in the other Romance languages: the (strong form of the) definite article followed by the comparative (which is analytic, made up of $m a i$ 'more' followed by an adjective, e.g., cel msg $_{\text {mai bun unt 'the }}$ msg more good butter' 'the best butter', cele fempl $_{\text {fai }}$ bune eleve 'the fempl more good $_{\text {fempl }}$ students fempl ' 'the best women students'). Romanian differs from the other Romance languages in that the comparative forms of mult 'much' and mulţi 'many' are also analytic (whereas in the other Romance languages they are suppletive, e.g., French plus).

${ }^{5}$ The proportional reading should be carefully distinguished from the comparative superlative reading, which in English is signalled by the presence of the, e.g., Who read the most books? In Romanian (and in many other languages, e.g., Hungarian or German) the definite article also appears in the proportional use.

${ }^{6}$ Note that whereas in (8) the plural NP boys was translated as a set of singular individuals, the same plural NP translates as a set of pluralities in (12). The reason for the set-of-pluralities denotation assumed in (12) is that the nuclear scope is filled with a collective predicate, which denotes a set of pluralities; hence a set of pluralities is also needed in the restrictor. Compare (8) and (11), where the nuclear scope is filled with a set of singular individuals and correlatively a set of singular individuals needs to appear in the restrictor. Although it is somewhat 
Two types of most

$$
\begin{aligned}
& \mid\{\mathrm{X}: \operatorname{boys}(\mathrm{X})\} \cap\{\mathrm{X} \text { : gathered }(\mathrm{X})\} \mid> \\
& \mid\{\mathrm{X} \text { :boys }(\mathrm{X})\}-\{\mathrm{X} \text { : boys }(\mathrm{X})\} \cap\{\mathrm{X} \text { : } \operatorname{gathered}(\mathrm{X})\} \mid
\end{aligned}
$$

This formula says: take the set of pluralities of boys and intersect it with the set of pluralities who gathered; this gives us the set of all pluralities of boys that gathered; we then need to take the complement of that set wrt the set of all pluralities of boys (by removing the members of the set of pluralities of boys that gathered from the set of all pluralities of boys); finally we need to check whether the cardinality of the first set is greater than the cardinality of the second. But this is not the correct truth condition: the formula asks us to compare the cardinalities of sets of pluralities, whereas the intuitive interpretation requires comparing cardinalities of sets (or sums) of atomic individuals.

Let us now observe that in both English and Romanian a non-partitive MOST also rules out the collective construal of examples built with mixed predicates in the nuclear scope. Thus, the examples in (13) cannot be used in the indicated scenario, and the same holds for the corresponding Romanian examples built with cei mai mulţ:

(13) [Scenario: Seven out of the ten boys at the party together lifted the piano once; there were no other liftings of the piano.]

a. \#Most boys at the party lifted the piano.

b. \#Most boys who were at the party lifted the piano.

This observation was made by Brisson (1998) for all and was extended to most by Nakanishi \& Romero (2004). These authors do not relate this generalization to the Roberts-van der Does generalization and Crnič (2009), who proposes an account for Nakanishi \& Romero's (2004) generalization, explicitly leaves collective predicates aside. The analysis proposed above straightforwardly extends to examples of this type. Indeed, the examples in (13) are true in the indicated scenario iff the condition in (14) is satisfied. But again, this condition asks us to compare cardinalities of sets of pluralities whereas according to our linguistic intuition the interpretation of MOST involves comparing cardinalites of sets of atoms:

$$
\begin{aligned}
& \mid\{\mathrm{X}: \operatorname{boys}(\mathrm{X})\} \cap\{\mathrm{X} \text { : lift-the-piano }(\mathrm{X})\} \mid> \\
& \mid\{\mathrm{X} \text { boys }(\mathrm{X})\}-\{\mathrm{X} \text { : boys }(\mathrm{X})\} \cap\{\mathrm{X} \text { : lift-the-piano }(\mathrm{X})\} \mid
\end{aligned}
$$

We may thus conclude that:

troublesome, the fact that the plural NP translates in two different ways is consistent with the hypothesis that the plural marker is semantically empty: Regardless of morphological plural marking, a count NP in the complement position of a Determiner, in particular most, will translate either as a set of singular individuals or a set of pluralities depending on the denotation of the nuclear scope. 
(15) The set-restrictor MOST allows a distributive predicate (as well as a distributively interpreted mixed predicate) but disallows a collective predicate (as well as a collectively interpreted mixed predicate) in its nuclear scope.

(15) is most likely a semantic universal: indeed, the generalization concerns semantic properties (set-denotation of the restrictor, distributive vs collective predicate); moreover, we have shown that this generalization holds over and above the crosslinguistic variation regarding the morphosyntactic complexity of MOST (the superlative of MANY).

\subsection{Set-restrictor MOST and mass quantification}

Note now that mass quantification is also disallowed with a set-restrictor MOST. Examples (16)a-c are from Matthewson (2001:174), who attributes them to V. Dayal (p.c.); (16)d is my example: ${ }^{7}$

(16) a. *Most milk in the fridge is sour.

b. *I shoveled most snow that was in this yard.

c. * Most mud that you traipsed in the house ended up on my rug.

d. *Most furniture in this house is broken.
a. *Cel mai mult lapte din frigiderul ăsta e acru. THE MORE MUCH milk in fridge-the this is sour
b. *Cea mai multă mobilă din această casă e veche. $\mathrm{THE}_{\text {fem }}$ MORE MUCH fem furniture in this $\mathrm{Sem}_{\text {fem }}$ house is old

The reader may have noticed that mass NPs are acceptable in the restrictor of most in certain examples in English, e.g., Most milk from old goats is sour, Most water is liquid. This does not, however, threaten the validity of our generalization concerning the impossibility for the set-restrictor MOST to function as a massquantifier, since in these examples, the bare NP is arguably kind-referring, hence we are not dealing with the set-restrictor most, but rather with the entity-restrictor most (see Dobrovie-Sorin 2013 and Section 5 below).

\section{Entity-restrictor most}

In this section we will provide an analysis for examples of the type in (1)b, built with an entity-restrictor most. The strategy will be to extend Higginbotham's

\footnotetext{
${ }^{7}$ In both languages, relative superlative readings of MOST NPmass are allowed, e.g., Romanian Cine a băut cel mai mult vin? 'Who drank the most wine?'.
} 
Two types of most

(1994) analysis from mass quantifiers to the collective quantifier most, i.e., to the plurality-restrictor most that takes a collective predicate (or a collectively interpreted mixed predicate) in the nuclear scope. This is justified by the parallelism between collective and mass quantifiers. In the previous section we have shown that both types of quantifiers disallow a set-denoting NP in their restrictor. In this section we are interested in entity-denoting restrictors, which are allowed with both collective quantifiers and mass quantifiers. Thus, parallel to the acceptability of collective quantifiers illustrated in (1)b, we find that mass quantifiers are also allowed with entity-denoting restrictors:

(18) a. Most of the milk in the fridge is sour.

b. I shoveled most of the snow that was in this yard.

c. Most of the mud that you traipsed in the house ended up on my rug.

$\mathrm{d}$. Most of the furniture in this house is broken.

This urges us to attempt a unified analysis of entity-restrictor mass and collective quantifiers. My proposal will build on Higginbotham 1994 (Section 4.1). I will then briefly present an alternative analysis of the entity-restrictor most due to Matthewson 2001 (Section 4.2).

\subsection{From mass quantifiers to collective quantifiers}

According to Higginbotham 1994, mass Qs do not denote relations between two sets (or equivalently, functions from sets into generalized Quantifiers, $\mathrm{Q}_{<\mathrm{et},<\mathrm{et}, \mathrm{t}>>}$ ) but rather relations between two entities (or functions from entities into sets $\left.\mathrm{Q}_{<\mathrm{e}, \mathrm{et}>}\right):^{8}$

(19) Mass quantifiers denote relations between two entities.

The two entities are respectively supplied by the DP in the restrictor and by the maximal sum obtained by applying a nominalizing operator to the predicate in the nuclear scope. Concretely, examples of the type in (18) are true iff truth conditions of the type in (20) are satisfied:

(20) $\mu([[$ the milk $] \cap \sigma X . \operatorname{sour}(X))>\mu([[$ the milk $]]-[[$ the milk $]] \cap \sigma X . \operatorname{sour}(X))$

In words, (20) requires that the measure $\mu$ of the sour milk (i.e., the meet $\cap$ of the maximal sum of milk $(\sigma \mathrm{X}$. milk $(\mathrm{X}))$ and the maximal sum of the sour entities "all

${ }^{8}$ This type of analysis of mass quantifiers can also be found in Roeper 1983 and Lønning 1987, who proposed it for all and some. Higginbotham extended the proposal to all mass quantifiers, in particular to most, and in order to do so, he introduced measure functions.

${ }^{9}$ Higginbotham's own examples are generic, e.g., Most water is liquid, the analysis of which will be taken up in Section 5. 
that is sour" $(\sigma \mathrm{X} . \operatorname{sour}(\mathrm{X})))$ is larger than the complement of that product wrt to the overall milk.

The type of representation in (20), due to Dobrovie-Sorin (2014), is a revised version of Higginbotham's (1994: 456) own proposal, in which Higginbotham's (1994) generalized join operator notated $\sum$ has been replaced by Sharvy's 1980 Maximality operator, notated $\sigma$.

In view of accounting for the homogeneity (or rather divisiveness) constraint on collective predicates in the nuclear scope of quantifiers, Dobrovie-Sorin (2014) proposes that collective quantifiers are of the same semantic type as mass quantifiers:

(21) Collective most denotes a relation between two pluralities (rather than two sets of pluralities).

The two pluralities are respectively supplied by the DP in the restrictor and by the plurality obtained by applying the maximality operator to the collective predicate in the nuclear scope. Thus, the example in (1)b, repeated as (22) below, is true iff (23) is satisfied. Note that in this case, the measure function $\mu$ is the cardinality function:

(22) Most of [DPthe boys] gathered in this room.

(23) $\mu([[$ the boys $]] \cap \sigma \mathrm{X}$.gathered $(\mathrm{X}))>$ $\mu([[$ the boys $]]-([[$ the boys $]] \cap \sigma X$.gathered $(X)))$

The truth-condition stated in (23) can be computed because meet can apply to two entities provided that they can be assigned a part-whole structure, and this condition is satisfied in examples like (22): the plurality of boys is made up of atomic boys and the plurality of gathering people is made up of several pluralities of gathering people.

Although this is not directly relevant here, let me note that a plural-entityrestrictor allows both the collective and the distributive readings of mixed predicates in the nuclear scope:

(24) Most of the boys sang a song.

The two interpretations of (24) are read off the LFs in (25)a-b, both of which are written on the model of (23):
a. $\mu([[$ the boys $]] \cap \sigma X$.sang-a-song $(X))>$ $\mu([[$ the boys $]]-([[$ the boys $]] \cap \sigma X$. sang-a-song $(X)))$
b. $\mu([[$ the boys $]] \cap \sigma \mathrm{X}$.*sang-a-song $(\mathrm{X}))>$ $\mu\left([[\right.$ the boys $]]-\left([[\right.$ the boys $]] \cap \sigma X .{ }^{*}$ sang-a-song $\left.\left.(X)\right)\right)$

In both cases, MOST denotes a relation between two plural entities, the sum denoted by the boys and the maximal sum of individuals that sang a song. 
Two types of most

Depending on whether the predicate sang a song is pluralized or not (pluralization is indicated by Link's star operator), we get the maximal sum of individuals that together sang a song (see (25)a, without pluralization) or the maximal sum of individuals such that each of them sang a song (see (25)b, with pluralization).

\subsection{Matthewson's analysis of the plurality-restrictor most}

Based on her work on St'at'imcets (a language in which all quantifiers have fullfledged DP restrictors), Matthewson (2001) analyzes English most (and all) as an entity-restrictor quantifier of the type stated in (26):

(26) MOST denotes a function from entities into Generalized Qs $\left(\mathrm{MOST}_{<e,<e t, t>>}\right)$.

Concretely, according to Matthewson's analysis, the representations of the example in (24) are as shown below, which are based on Crnic's (2009) representations:

(27) a. $\exists X . X \leq[[$ the boys $]]$ [sang a song $(X) \& \mu(X)>1 / 2 \mu([[$ the boys $]])]$

b. $\exists X . X \leq[[$ the boys $]][*$ sang a song $(X) \& \mu(X)>1 / 2 \mu([[$ the boys $]])]$

(27)a, which represents the collective reading, says that there is a plurality of boys that is a part of the boys and measures more than half of the boys and this plurality jointly sang a song. The pluralization of the main predicate indicated by the star operator in (27)b captures the distributive reading: the plurality is made up of individuals that individually sang a song.

Matthewson herself does not examine collective quantifiers (nor mass quantifiers), but her analysis, if correct, could also be used to represent examples of the type in (22):

(28) $\exists X . X \leq[[$ the boys $]]$ [gathered(X) \& $\mu(X)>1 / 2 \mu([[$ the boys $]])]$

For our present purposes, since all that matters is the entity-type of the restrictor, Matthewson's type of representation might work. There are, however, at least two reasons for preferring a Higginbotham-type of analysis. The first one is empirical, namely the fact that the Homogeneity (or rather the Divisiveness) Constraint on collective Q's ${ }^{10}$ can be explained if we assume Higginbotham's but not Matthewson's analysis (see Dobrovie-Sorin 2014). The second reason is theoretical: whereas Higginbotham's analysis relies on the standard relational

${ }^{10}$ According to Dobrovie-Sorin 2014, collective Q's (as well as mass Q's) are subject to a Divisiveness Constraint, which requires the predicates in their nuclear scope to be divisive. This constraint is a weaker version of the Homogeneity Constraint proposed by Bunt 1979, 1985, Lønning 1987 and Higginbotham 1994 for mass Q's, which requires homogeneous predicates in the nuclear scope. Dobrovie-Sorin 2014 argues that the weakening is necessary not only for collective, but also for mass Q's. 
analysis of quantificational Determiners (in this case most), Matthewson's proposal involves translating most in terms of an existential quantifier. The advantage of Matthewson's proposal is that the nominalization of the nuclear scope can be dispensed with. Under both analyses, collective quantifiers have entity-denoting restrictors.

\section{Back to non-partitive MOST}

In this section we will examine in more detail QPs built with a non-partitive MOST, i.e., QPs of the form MOST NP (where NP can be mass or plural), and we will discover that they are structurally ambiguous in English, the NP being analyzable either as a genuinely bare NP or as a kind-referring DP. I will start by providing evidence in favor of the 'null hypothesis' assumed at the outset of this paper, according to which no type-shifting of the restrictor should be allowed (Section 5.1). I will then examine kind-referring bare NPs in the restriction of MOST in English (Section 5.2). In Section 5.3 we will see that the possible kindreference of bare NPs in the restrictor of MOST observable in English is not a semantic universal, but rather a parametrized option, which is negatively set in Romanian (Section 5.3). Taken together, these observations show that Matthewson's 2001 claim that bare NPs in the restrictor of most (and all) are necessarily kind-referring in English is too strong. Consequently, Crnič's 2009 claim that the distributive readings of non-partitive most are due to the kindreference of its restrictor must itself be wrong.

\subsection{No type-shifting in the restrictor of MOST}

The analysis proposed above confirms the view that collective quantificational determiners do not denote relations between sets of (plural) entities but rather relations between (plural) entities or equivalently, functions from entities into sets of entities. ${ }^{11}$ As already made clear in $\S 4.1$ above, this analysis constitutes an extension to collective Qs of the analysis proposed by Higginbotham (1994) for mass quantifiers. It is however worth stressing that the details of my analysis differ from Higginbotham's implementation. Indeed, according to Higginbotham, the restrictor of most is a mass NP (type $<\mathrm{e}, \mathrm{t}>$ ) that ends up denoting an entity via nominalization, due to the default application of the generalized join operator notated $\sum::^{12}$

${ }^{11}$ Or functions from entities into generalized quantifiers, in case Matthewson 2001 is right.

${ }^{12}$ The reader may recall that in $\$ 4.1$ above I followed Dobrovie-Sorin 2014 in assuming that the operator needed in order to nominalize the scope of entity-restrictor MOST is Sharvy's Maximality operator $\sigma$. Here, I argue against Higginbotham's assumption that a nominalizing operator applies to the restriction, which is why I use Higginbotham's own hypothesis according to which the nominalizing operator is $\sum$. 
Two types of most

(29) Most water is liquid.

(30) a. [[NPWater]]: the property of being water, i.e., the set of quantities of water (type $<\mathrm{e}, \mathrm{t}>$ )

b. $\sum[[$ NPWater $]$ : the maximal sum of water (type e)

The problem is that this analysis cannot account for the unacceptability of examples of the type in (16), e.g. (16)a, repeated as (31) below:

(31) *Most milk in the fridge is sour.

Indeed, a default application of the maximality operator in the restriction of most incorrectly predicts that mass quantification with most should always be acceptable. Similarly, collective quantification is also expected to always be possible, contrary to the unacceptability of examples of the type in (1)a, repeated as (32):

(32) *Most [Npboys] gathered in this room.

As already explained in Section 3 above, the observed unacceptabilities can be explained only if we assume, contra Higginbotham 1994, that the type-shifting of the restrictor is not allowed:

(33) No type-shifting (no default application of $\sum$ or $\sigma$ ) applies to the restrictor of quantifiers.

Given (33), the examples in (31) and (32) are unacceptable because mass and collective Qs cannot denote relations between sets (see Section 3). This result is lost if we assume default type-shifting of the restrictor from set-denotation to entity-denotation.

Let me remind the reader that I do assume, following Higginbotham, the typeshifting of the nuclear scope, which is obligatorily triggered whenever the restrictor is entity-denoting.

\subsection{Kind-referring bare NPs in the restriction of most}

But why is it that a non-partitive most does allow mass quantification in examples such as (29), repeated (34)?

(34) Most water is liquid.

I will follow Dobrovie-Sorin 2013 in assuming that in this type of example the restrictor of most is filled with a kind-referring (type e) bare NP:

(35) Non-partitive most in English is structurally ambiguous: The bare NP in the restrictor is kind-referring or set-referring. (Dobrovie-Sorin 2013) 
Thus, the bracketed representation of (34) is as shown in (36), where the null Det $^{\circ}$ has the semantics of an intensional maximality operator (see Chierchia's 1998 Down operator), ${ }^{13}$ which applies to a set and yields the corresponding intensional maximal sum, i.e., the kind corresponding to the property denoted by the NP:

$\left[\left[_{\mathrm{QP}} \mathrm{most}\right]\left[\mathrm{DP}_{\mathrm{DPt}}\left[\left[_{\mathrm{DP}} \varnothing\right]\left[\mathrm{NP}_{\mathrm{N}} \mathrm{Water}\right]\right]\right]\right.$ is liquid.

Since kinds are a particular type of entity, we may extend to kinds the analysis proposed in Section 4 for restrictors referring to particular entities: in examples like (34) most denotes the relation between the kind (type e) water and the intensional sum of liquid stuff. The complication is that kinds are indeterminate/infinite entities, which cannot be measured with measure units (meters, liters, etc.). We must therefore resort to ratios, which can be used to measure parts of kinds wrt the kind itself: ${ }^{14}$ the measure of the whole (in this case the overall water) is 1 and the measure of any part of the whole is a ratio $r$ comprised between 0 and 1 . In order to check whether $(29) /(34)$ is true we would need:

(37) a. to calculate $\mathrm{r}=\operatorname{vol}(\sigma \mathrm{x}$. water(x) $\cap \sigma \mathrm{x}$. $\operatorname{liquid}(\mathrm{x})) / \mathrm{vol}(\sigma \mathrm{x}$. water(x))

b. to check whether $r>1 / 2^{15}$

Let us now consider again the English examples in (16)a-d; we repeat (16)a in (38):

(38) *Most milk in this fridge is sour.

Such examples are unacceptable because modifiers such as in this fridge, which refer to particular entities, prevent bare NPs from referring to kinds (recall Carlson's observations regarding parts of this machine); milk in this fridge can only be analyzed as a set-denoting bare NP, hence most must denote a relation between two sets, which is not allowed for mass quantification (see Section 3):

(39) $*\left[\left[_{\mathrm{QP}} \mathrm{most}\right]\left[_{\mathrm{NP}}\right.\right.$ milk in this fridge $]$ is sour.

Note that it is not modification per se that blocks kind-reference. Those modifiers that are compatible with kind-reference are allowed, in particular (certain) i-level predicates, e.g., black or from old goats in black cats or milk from old goats:

(40) Most milk from old goats is sour.

\footnotetext{
${ }^{13}$ Note that Chierchia himself uses the Down operator in order to derive the kind-reference of plural bare NPs, but does not use it for kind-referring mass bare NPs (for further discussion see Dobrovie-Sorin \& Pires-de Oliveira 2008, Dobrovie-Sorin 2013, 2014).

${ }^{14}$ Using ratios instead of measure units is possible because size is a ratio scale, which means that particular choices of measure units (for the same dimension) do not affect truth conditions.

15 In order to take into account the vagueness of MOST (see Solt 2011) we may assume that $r$ must be larger than some context-dependent proportion that is higher than $1 / 2$.
} 
(41) $\left[\left[_{\mathrm{QP}} \mathrm{most}\right]\left[{ }_{\mathrm{DP}}\left[\mathrm{Det}^{\circ} \varnothing\right]\left[{ }_{\mathrm{NP}}\right.\right.\right.$ milk from old goats $\left.\left.]\right]\right]$ is sour.

Given the parallelism between collective and mass quantification, and given that plural bare NPs can be kind-referring in English, they are expected to be allowed in the restriction of most built with a collective predicate in the nuclear scope. This expectation is indeed fulfilled:

(42) Most students gather in bars (rather than in student lounges).

$$
\left[\left[_{\mathrm{QP}} \mathrm{most}\right]\left[{ }_{\mathrm{DP}}\left[\left[_{\mathrm{Det}} \varnothing\right]\left[_{\mathrm{NP}} \text { students }\right]\right]\right]\right. \text { gather in bars. }
$$

The example in (42) is true iff the ratio between the sum of bar-gathering students and the overall sum of students is higher than at least $1 / 2$.

\subsection{Bare NPs across languages}

It is important to stress that the kind-reference of English bare mass NPs is not due to a nominalizing operator that would be introduced during the syntaxsemantics mapping whenever the semantic computation needs it. Rather, the nominalizing operator is syntactically present under the form of a null $\operatorname{Det}^{\circ}$ that has the semantics of an intensional maximality operator.

The possibility of a null $\operatorname{Det}^{\circ}$ to be interpreted as an intensional maximality operator is a parametrized option that yields crosslinguistic variation. The example in (44)a shows that Romanian (on a par with all the other Romance languages) is negatively specified wrt this parameter: In this language, bare NPs cannot be kind-referring in argument positions, ${ }^{16}$ and by the 'null hypothesis', they cannot be kind-referring in the restrictor of MOST either. A bare NP in the restrictor of MOST is therefore necessarily a set-denoting NP. This explains why the Romanian counterpart of (29)/(34) is unacceptable, as shown in (44)b:
a. *Apă e lichidă
Water is liquid
b. *Cea mai multă apă e lichidă THE MORE MUCH water is liquid

Given that in Romanian plural bare NPs cannot be kind-referring either (see (45)a for argument positions), we expect the unacceptability of (45)b, which is parallel to the unacceptability of (44)b:

$$
\text { a. *Studenţi se întîlnesc în baruri. }
$$

\footnotetext{
${ }^{16}$ Bare NPs in argument positions can only take existential readings, in which case they can be analyzed either as property-denoting bare NPs (van Geenhoven 1998, Dobrovie-Sorin 2007, Dobrovie-Sorin \& Laca 2003, a.o.) or as DPs (headed by a null Det ${ }^{\circ}$ ) that denote existential generalized Qs over amounts (Dobrovie-Sorin \& Beyssade 2012, Dobrovie-Sorin \& Giurgea 2015).
} 
Dobrovie-Sorin

Students SE gather in bars

(intended reading: 'Students gather in bars.')

b. *Cei mai mulţi studenţi se întîlnesc în baruri.

THE MORE MANY students SE gather in bars

(intended reading: 'Most students gather in bars.')

In order to express the intended meanings of (44)b and (45)b, Romanian must use definite DPs in the restriction:

(46) a. Cea mai mare parte a apei e lichidă.

THE MORE BIG part of water- the ${ }_{\text {Gen }}$ is liquid

'Most water is liquid.'

b. Majoritatea studentilor se întîlnesc în baruri.

majority-the students-the Gen $\mathrm{SE}$ gather in bars

'Most students gather in bars.'

In sum, Romanian differs from English insofar as plural and mass bare NPs cannot be kind-referring, which explains the contrasts (29)/(34) vs (44)b and (42) vs (45)b.

Because English bare NPs can be kind-referring, the contrast between the distributive and collective non-partitive MOST can be observed in this language only in non-generic contexts, where the kind-reference of the restrictor is blocked. In Romanian, on the other hand, the contrast can be observed even in generic contexts, because in this language the NP-complements of MOST are necessarily set-denoting. And set-denoting restrictors are allowed for distributive quantification, but not for mass or collective quantification. The Romanian pattern is predicted to appear in all the languages in which bare NPs cannot be kindreferring in argument position. This prediction is verified for Hungarian (although Szabolcsi (2012a,b, 2013) herself does not make this generalization, the data she provides indicate that our prediction is correct).

Let me finally remind the reader that the unacceptability of (45)b should not be taken to indicate that set-referring plural bare NPs are always ruled out in the restrictor of MOST in Romanian. Indeed, such a configuration is allowed in examples that involve distributive construals, because in this case MOST denotes the relation between two sets of singular individuals (see Section 2 above).

\subsection{Bare NPs in the restrictor of MOST are not necessarily kind-referring}

Some of the English examples examined in Section 5.3 show that in this language, bare (plural and mass) NPs in the restrictor of MOST can be kindreferring, but taken together, the empirical data of English and Romanian that we brought up implicitly argue against Matthewson's 2001 stronger claim that: 
Two types of most

(47) The NP-restrictor of most is always kind-referring in English.

Below we show that (47) is indeed too strong.

The first argument relates to Romanian examples of the type shown in (11), [Cei mai multi] [NPelevi] au plecat devreme 'Most students left early'. Since in this language, the complement of cei mai mulţi 'most' cannot be kind-referring, we must assume that it is set-denoting. And since set-denotation is uncontroversially the 'null hypothesis', it is stipulative to assume that in English, the NP-restrictors of most cannot be set-referring.

Consider next the contrast in English between acceptable and unacceptable mass quantification (see (40) vs (38)): If mass bare NPs in the restrictor of most were always kind-referring, this type of contrast would be puzzling (indeed, Matthewson 2001 observes that but does not explain why examples of the type in (38) are unacceptable). Under the view that the kind-reference of bare NPs is blocked in certain configurations, the observed unacceptability can be explained as being due to the fact that mass quantifiers cannot denote relations between sets.

Let us next consider the following contrast, which concerns collective quantifiers:

(48) Most students (of mine) gather in bars (rather than in student lounges).

(49) *Most students (of mine) will gather in the hall.

If in both examples students (of mine) was kind-referring, the contrast would be puzzling. Under my own proposal, the contrast (48) vs (49) can be easily explained: collective quantifiers allow kind-referring restrictors, hence the acceptability of (48); ${ }^{17}$ but a bare NP can be interpreted as kind-referring only if the predicate in the nuclear scope is either an individual-level or a habitual predicate but not if it is a stage-level predicate. Consequently, in an example such as (49) the bare NP cannot be kind-referring, the only option being that it denotes a set of plural entities. But collective quantifiers cannot denote a relation between sets of plural entities (Section 3), hence the observed unacceptability. In sum, the example in (49) is unacceptable because of two conflicting requirements, the setdenotation of the restrictor and the collective interpretation, which is imposed by the lexical properties of the predicate in the nuclear scope.

\subsection{On the distributivity of plural bare NPs in the restrictor of MOST}

Based on Matthewson's 2001 assumption in (47), Crnič 2009 attributes the obligatory distributive reading of non-partitive most in examples like (50) to the

\footnotetext{
${ }^{17}$ Note that given my proposal we expect to find examples built with a kind-referring restrictor and a collectively interpreted mixed predicate. So far I have not been able to find examples of this kind, neither with a plural bare NP in English, nor with a definite plural in Romanian.
} 
kind-reference of its restrictor: ${ }^{18}$

(50) Most boys at the party lifted the piano.

(51) A kind-restrictor (as opposed to a particular-entity-restrictor) most necessarily yields distributive readings.

The example in (48) shows that (51) is too strong, because a kind-restrictor most appears to be compatible with a collective predicate in the nuclear scope.

Further evidence against (51) is supplied by Romanian (and by all the languages in which definite plurals can be kind-referring, e.g., all Romance languages or Hungarian, among many others). In this language, MAJORITY allows a collective predicate in its nuclear scope and a kind-referring DP restrictor, as in (46)b above or (52):

(52) Majoritatea studenţilor se întîlnesc în baruri.

Majority-the students-the ${ }_{\text {Gen }}$ SE gather in bars.

'Most students gather in bars.'

Note however that Crnič (2009) himself explicitly leaves collective predicates aside and concerns himself only with examples of the type in (50), where the nuclear scope is filled with mixed predicates. One might then try to defend Crnič's proposal for this type of example. But to do so, one would need to assume a more restricted version of (51) and explain why only mixed predicates - as opposed to collective predicates - in the nuclear scope yield such an interpretive effect on the kind-restrictor most. Note moreover that whatever that explanation could be, it cannot extend to the Romanian counterparts of the examples in (50), because in this language, bare NPs in the restrictor of MOST cannot be kindreferring:

(53) Cei mai mulţi invitaţi au ridicat pianul. (distributive; *collective) THE MORE MANY guests have lifted piano-the 'Most guests lifted the piano.'

According to my own proposal, the obligatory distributivity of examples built with a plural bare NP in the restrictor of most and a mixed predicate in the nuclear scope ((50) for English and (53) for Romanian) can be explained in exactly the same way as the unacceptability of a collective predicate in the nuclear scope: in

${ }^{18}$ According to Crnič 2009 the presence of a kind-referring restrictor triggers the insertion of a GEN operator in the nuclear scope, and this induces distributivity. Note that in order to obtain kind-reference for a bare NP modified by an s-level adjunct (or relative clause), Crnič assumes that the bare NP, which starts out as kind-referring, is shifted to set-denotation in order to allow intersection with the modifier and then the product set is shifted back to kind-reference. These type-shiftings are stipulative: they are assumed only in order to maintain the view that the complement of most is kind-referring. Note that, contrary to a remark by a SALT reviewer, it is not true that Crnič 2009 says that examples of the type in (50) can have collective readings. 
Two types of most

order for the collective reading to be possible, a set-restrictor MOST would need to denote a relation between two sets of plural entities, but this is disallowed (Section 3). The distributive reading is possible, since in this case MOST denotes a relation between two sets of singular entities, as standardly assumed in GQT analyses (Section 2).

\section{Conclusions}

I have argued that the unacceptability of collective predicates in the nuclear scope of non-partitive MOST illustrates a semantic universal according to which collective quantifiers cannot denote relations between sets of plural entities, but only relations between plural entities. Collective predicates are allowed to occur in the nuclear scope of partitive MOST because this quantifier denotes a relation between two plural entities. This proposal, which accounts for collective and mass quantification in a unitary fashion, was illustrated with data from Romanian and English. These two languages show remarkable parallelisms in the behavior of both partitive and non-partitive MOST, the only differences arising from the fact that in English - in contrast to Romanian - bare NPs can be kind-referring. Crucially however, English bare NPs are not necessarily kind-referring (contra Matthewson 2001 and Crnič 2009).

\section{References}

Boolos, George. 1984. To be is to be a value of a variable (or to be some values of some variables). Journal of Philosophy 81, 430-50.

Brisson, Christine. 1998. Distributivity, maximality, and floating quantifiers. Ph.D. dissertation, Rutgers University.

Brisson, Christine. 2003. Plurals, all, and the nonuniformity of collective predication. Linguistics and Philosophy 26, 129-184.

Chierchia, Gennaro, 1998. Reference to kinds across language. Natural Language Semantics 6(4). 339-405.

Crnič, Luka. 2009. On the (non-) cumulativity of cumulative quantifiers. In Martin Prinzhorn, Viola Schmitt and Sarah Zobel (eds.), Sinn und Bedeutung (SuB) 14, 117-133.

Dobrovie-Sorin, Carmen, and Brenda Laca. 1996. Generic bare NPs. Unpublished manuscript.

Dobrovie-Sorin, Carmen. 1997. Types of predicates and the representation of existential readings. In Aaron Lawson (ed.), Semantics and Linguistic Theory (SALT) 7, 117-134. Cornell University Press. 
Dobrovie-Sorin, Carmen, and Brenda Laca. 2003. Les noms sans déterminant dans les langues romanes. In Danièle Godard (ed.), Les Langues romanes. Problèmes de la phrase simple: 235-281, Editions du CNRS.

Dobrovie-Sorin, Carmen, and Alda Mari. 2007. Generic plural indefinites: Sums or groups? In Emily Elfner and Martin Walkow (eds.), North East Linguistics Society (NELS) 37, 205-218.

Dobrovie-Sorin, Carmen, and Roberta Pires De Oliveira. 2008. Reference to kinds in Brazilian Portuguese: Definite singulars vs. bare singulars. In Alte Grønn (ed.), Sinn und Bedeutung (SuB) 12, 107-121. Oslo: ILOS.

Dobrovie-Sorin, Carmen. 2012. Generic plural and mass indefinites. In Alda Mari, Claire Beyssade and Fabio del Prete (eds.), Genericity, 93-115. Oxford: Oxford University Press.

Dobrovie-Sorin, Carmen \& Claire Beyssade. 2012. Redefining Indefinites, Studies in Natural Language and Linguistic Theory, vol. 85. Dordrecht: Springer.

Dobrovie-Sorin, Carmen. 2013. Most: The view from mass. In Maria Aloni, Michael Franke and Floris Roelofsen (eds.), Amsterdam Colloquium (AC) 19, 99-107.

Dobrovie-Sorin, Carmen. 2014. Collective quantification and the homogeneity constraint. In Semantics and Linguistic Theory (SALT) 24, 453-472, Ithaca, NY: CLC.

Dobrovie-Sorin, Carmen, and Ion Giurgea. 2015. Weak reference and semantic incorporation. In Olga Borik and Berit Gehrke (eds.), The Syntax and Semantics of Pseudo-Incorporation, 88-125. Brill.

van der Does, Jaap. 1993. Sums and quantifiers. Linguistics and Philosophy 16: $509-550$.

van Geenhoven, Veerle. 1998. Semantic Incorporation and Indefinite Descriptions. Palo Alto: CSLI.

Hackl, Martin. 2009. On the grammar and processing of proportional quantifiers: Most versus more than half. Natural Language Semantics 17(1), 63-98.

Higginbotham, James. 1994. Mass and count quantifiers. Linguistics and Philosophy 17, 447-480.

Kratzer, Angelika. 1995. Stage-level and individual-level predicates. In Gregory N. Carlson and Francis Jeffry Pelletier (eds.), The Generic Book, 125-175. University of Chicago Press.

Link, Godehard. 1983. The logical analysis of plurals and mass terms: A latticetheoretical approach. In Bäuerle, Reiner, Schwarze, Christoph, and von Stechow, Arnim (eds.), Meaning, Use and Interpretation of Language, 303323. Berlin, Germany: de Gruyter.

Landman, Fred. 1989. Groups, I. Linguistics and Philosophy, 12(5), 559-605.

Landman, Fred. 1991. Structures for Semantics. Dordrecht: Kluwer.

Lønning, Jon Tore. 1987. Mass terms and quantification. Linguistics and 
Two types of most

Philosophy 10(1), 1-52.

Matthewson, Lisa. 2001. Quantification and the nature of crosslinguistic variation. Natural Language Semantics 9(2), 145-189.

Nakanishi, Kimiko and Maribel Romero. 2004. Two constructions with most and their semantic properties, In Keir Moulton and Matthew Wolf (eds.), North East Linguistics Society (NELS) 34, 453-468.

Rayo, Agustín. 2002. Word and Objects. Nô̂s, 36: 436-64.

Roberts, Craig. 1987. Modal Subordination, Anaphora and Distributivity, Ph.D. dissertation, Amherst.

Roeper, Peter. 1983. Semantics for mass terms with quantifiers. Noûs 17, 251-26.

Solt, Stephanie. 2011. How many Most's. In Reich, Ingo et al. (eds.), Sinn und Bedeutung ( $\mathrm{SuB})$ 15, 565-579. Universaar - Saarland University Press: Saarbrücken, Germany.

Szabolcsi, Anna. 2012a. Word-less compositionality: Case studies in quantification. Colloquium at UCLA, 2-24.

Szabolcsi, Anna. 2012b. Compositionality without word boundaries: (The) more and (the) most. In Semantics and Linguistic Theory (SALT) 22, 1-25. Ithaca, NY:

CLC Publications.

Carmen Dobrovie-Sorin

CNRS-LLF

Université Paris 7

carmen.sorin@linguist.univ-paris-diderot.fr 